\title{
ROCANDOLFO AL SERVICIO DE CARLOS V: WILHELM VON ROGENDORF, COMENDADOR DE OTOS $(1481-1541)^{1}$
}

\author{
ANNA MUR I RAURELL \\ Instituto Histórico Austríaco
}

\begin{abstract}
Y la Católica Magestad mandó a un cavallero alemán muy onrado, que avía por nombre Rocandolfo, el qual parecía tío de Josephe, o al embaxador de Rusia [...] y a don Beltrán de Robles [...] los quales hizieron cosas tan señaladas en esta guerra de los moros que a Dios hizieron servicio y a su Magestad no menos.

Francés de ZúÑIGA, Crónica burlesca del Emperador Carlos $V$.
\end{abstract}

Rocandolfo, Roguendolfo, Rochendorff, Roquendolf, pues de estas diversas maneras se castellanizó su apellido y así ha pasado incluso a textos modernos, no es otro que Wilhelm von Rogendorf, un noble originario de la Baja Austria, cuya vida transcurrió en los campos de batalla de Europa, a la sombra del emperador Carlos $\mathrm{V}$, para quien luchó y que le concedió honores y bienes que demuestran la alta estima en que le tenía ${ }^{2}$. Su

'Este artículo es producto de las investigaciones realizadas para el proyecto que el Instituto Histórico Austriaco con sede en Madrid lleva a cabo sobre las Ordenes Militares españolas en Centroeuropa durante los siglos XVI y XVII, de próxima publicación. Agradezco su ayuda a Dña. Isabel Aguirre, al Dr. Christian Beaufort-Spontin, a S.A.I. Dr. Michael Salvator Habsburg-Lothringen, a Dña. Catherine Martet y a Dña. Victoria Smith.

Abreviaturas: AGS (Archivo General de Simancas), AHN (Archivo Histórico Nacional), $\mathrm{CjH}$ (Consejo y Juntas de Hacienda), OM (Ordenes Militares).

${ }^{2}$ Estudio básico sobre la familia Rogendorf es el de Josef BERGMANN, Über die Freiherren und Grafen zu Rogendorf, Freiherren auf Mollenburg, "Sitzungsberichte der phil.-histor. Classe d. kaiserl. Akademie d. Wissenschaften", 7, Wien, 1851, pp. 519-626. Más recientemente, pero 
presencia en España de 1522 a 1528, período que principalmente trata este artículo, tiene precedentes en el siglo XIV cuando el también noble tirolés Oswald von Wolkenstein, a inicios de siglo $(1415)^{3}$, y el noble de Baja Austria Albrecht von Pottendorf $(1431)^{4}$, viajaron por la Península para luchar contra los musulmanes.

La familia Rogendorf procedía de una vieja estirpe de Estiria. A mediados del siglo XV se trasladaron de allí con el emperador Federico III a la Baja Austria, donde adquirieron muchos bienes. Entraron en posesión del castillo y señorío de Pöggstall, situado a unos cien $\mathrm{km}$. de Viena, en el año 1478. Fueron la familia más significativa que poseyó este castillo, llamado también Rogendorf, que a través de ellos recibió la forma y hasta ahora ha mantenido su nombre.

El primer señor de Pöggstall fue Caspar von Rogendorf. Su padre, Sigmund von Rogendorf, fue escribano y administrador en Estiria donde consiguió una posición de prestigio. Caspar fue partidario del emperador Federico III quien durante su gobierno encontró en él un hombre de gran lealtad y perseverancia. A través de su matrimonio con Margaretha, hija única de Erasmus de Wildhaus y la última de su estirpe, Caspar pudo aumentar sus propiedades paternas de forma cuantiosa. Adquirió después de la venta de sus propiedades en Estiria diversos bienes y señoríos en la Baja Austria y alcanzó a través de arrendamientos y préstamos considerables riquezas lo que le permitió ayudar al emperador con dinero. Este supo

basándose en gran parte en el exhaustivo trabajo de Bergmann, Hol Herbert NEIDHART, Aus der Geschichte Pöggstalls: Caspar von Rogendorf, der erste seines Geschlechtes als Herr von Pöggstall, "Heimatkundliche Beilage zum Amtsblatt der Bezirkshauptmannschaft Melk" 15 (1989) n. 4 (abril) p. 2 ; 15 (1989) n. 5 (mayo), pp. 1-2; 15 (1989) n. 6 (junio), pp.1-2; 15 (1989) n. 7 (julio), p. 1.- NEIDHART, Aus der Geschichte Pöggstalls: Die Erhebung zur Reichsfreiherrschaft unter Wilhelm, Wolfgang und Georg von Rogendorf, "Heimatkundliche Beilage zum Amtsblatt der Bezirkshauptmannschaft Melk" 15 (1989) n. 11 (noviembre), p. 2; 15 (1989) n. 12 (diciembre), p.1 ; 16 (1990) n.1 (enero), pp. 1-2; 16 (1990) n. 2 (febrero), pp. 1-2. Los datos de este artículo proceden de estos dos trabajos, cuando no se indica expresamente la fuente. Rogendorf hasta ahora había sido considerado como un "tudesco procedente de la corte borgoñona" y su apellido castellanizado bajo las formas Rocandolfo, Roguendolfo. V. Francisco FERNÁNDEZ IZQUIERDo, La Orden Militar de Calatrava en el siglo XVI, Madrid, 1992, p. 95.

${ }^{3}$ Karl Friedrich Rudolf, La imagen de la Península Ibérica en Centroeuropa en la época del Tratado de Tordesillas, "El Tratado de Tordesillas y su época", III, Madrid, 1995, pp. 1907-1923.

${ }^{4} \mathrm{Karl}$ Friedrich Rudolf, Reisen und Beziehungen zwischen Österreich und Spanien in Spätmittelalter und Renaissance. "Spanien und Österreich in der Renaissance. Akten des fünften Spanisch-Österreichischen Symposions, 21-25 September 1987 en Wien", ed. Wolfram KRÖMER, Innsbruck 1989 (=Innsbrucker Beiträge zur Kulturwissenschaft, Sonderheft 66), pp. 35-36. 
apreciar la fidelidad y ayuda de los Rogendorf y los recompensó con la concesión de honores y empleos.

Ya en 1470 le dio el señorío de Weitenegg y rentas en Ispertal en depósito, en 1475 otorgó a su "truchsess" (jefe de la organización de la corte) y castellano de Weitenegg el pleno poder, en 1478 fue Caspar encargado de Ybbs y en 1479 se convirtió en castellano de Werfenstein. El 7 de diciembre de 1478, como hemos dicho, el emperador Federico dio a su camarero Caspar von Rogendorf el castillo de Pöggstall. Asimismo en 1478 adquirió el castillo de Rosenburg (que vendió de nuevo en 1487), en 1479 el castillo de Ottenschlag, en 1480 el señorío de Guntersdorf (del cual su nieto Christoph en 1537 recibió el título de conde), en 1487 el castillo despoblado y la castellanía de Pöbring.

El 4 de noviembre de 1480 Caspar y su hermano Balthasar, debido a sus servicios y a los de su fallecido padre, fueron admitidos al rango de los caballeros y alcanzaron en dicho diploma para sí y sus herederos masculinos legítimos el derecho de sellar con cera roja, lo que Caspar ya había conseguido unos años antes.

El rey húngaro Matías Corvino, que conquistó Austria y reinaba desde 1485 en Viena, siguió favoreciendo a su "especialmente amado" Caspar. En 1487 recibió de Matías los castillos Pöggstall y Ottenschlag en feudo.

En 1491 Caspar consiguió del emperador el castillo de Steyr con todos los derechos y todos los beneficios como castellano, además se convirtió en castellano de los castillos y del señorío de Steyr, cargo que ocupaba aún en 1493. En 1492 dirigió, ya que el rey Maximiliano se encontraba fuera de su tierra, junto con Niklas von Liechtenstein el gobierno de Austria. En un diploma del año 1494 se describe a sí mismo como uno de los "gobernadores y regentes del regimiento de la tierra de Austria, Estiria, Carintia y Carniola".

Una enumeración sucesiva de honores, empleos y propiedades, sin pretender una totalidad, sólo haría que subrayar la significativa posición de los Rogendorf.

Caspar murió el 18 de octubre de 1506 en Guntersdorf y fue enterrado en la iglesia de su castillo en Pöggstall. La losa de mármol rojo de su sepultura ahora está, como las otras losas de los Rogendorf, en la iglesia de santa Anna. La inscripción reza: "En el nombre de Dios aquí yace enterrado Caspar von Rogendorf que murió en el día de san Lucas de 1506". 
Se casó en dos ocasiones. Su primera mujer fue como ya se ha dicho Margaretha von Wildhaus, la única hija de Erasmus de Wildhaus y su esposa Elisabeth de Auersperg. Con ella tuvo cinco hijos: Christoph, Sigmund, Wilhelm, Wolfgang y Georg y algunas hijas (entre ellas Elisabeth que más tarde fue esposa del conde Niklas de Salm). Una interesante representación de la familia de Caspar se encuentra en el castillo de Rosenburg. En el cuadro "Coronación de María" del año 1493 Caspar aparece con cinco hijos y su mujer con tres hijas, entre ellos se hallan las armas de los Rogendorf (un muro dorado con tres almenas, por encima una estrella dorada de seis puntas con fondo azul) y las de los Wildhaus. Margaretha murió en 1492. $\mathrm{Al}$ año siguiente se casó con Barbara von Zelking, con la que al parecer tuvo otra hija.También está enterrada en Pöggstall.

De los hijos de Caspar, Christoph murió aún joven. Sigmund, nacido en 1480, recibió en feudo de Maximiliano I el castillo de Pöggstall tras la muerte de su padre, para sí y como transmisor del feudo a sus hermanos Wilhelm, Wolfgang y Georg. Sin embargo sobrevivió a su padre sólo nueve meses y murió - según la lápida funeraria de la iglesia de santa Ana- el día de santa Ana en el año 1507, siendo castellano de la ciudad de Steyr.

Los hermanos Wilhelm, Wolfgang y Georg poseyeron desde el inicio sus bienes heredados juntos y se esforzaron, como ya lo hiciera su padre, en incrementar su riqueza.

Wilhelm, nuestro Rocandolfo, el más famoso de la estirpe, nació el 20 de noviembre de 1481. Con trece años, como era habitual en la época, en 1494 entró al servicio de Felipe el Hermoso como paje en los Países Bajos. Fue promovido el 13 de octubre de 1504 a consejero y camarero de éste; el 8 de diciembre de 1507 se le nombra consejero del emperador Maximiliano I. De igual manera Rogendorf ejerció su talento en el campo de batalla. Mandó un cuerpo de ejército cerca del pueblo y castillo de Calliano en los alrededores de Rovereto contra los venecianos y sus aliados, venciéndoles y recibiendo en el curso de esta acción un balazo en la cadera derecha. El Emperador concluyó un armisticio de tres años con Venecia el 6 de junio de 1508 .

Junto a sus misiones fundamentalmente guerreras el emperador Maximiliano I encargó a Rogendorf misiones diplomáticas. Le concedieron en 1509 plenos poderes para concluir la paz con Luis XII de Francia. En el mismo año recibió junto a los estadistas Mercurino Gattinara y Andrea del Burgo de Cremona también el joven Rogendorf el encargo de mediar entre el rey de Francia y Carlos de Egmont, quien desde hacía dos años como 
instrumento de Francia había comenzado otra vez los disturbios en Geldres. Según una instrucción imperial, fechada en Trento el 1 de diciembre de 1509, viajó con los dos hombres antes mencionados a Fernando el Católico para terminar algunas controversias a propósito del gobierno tutelar en Castilla.

El Emperador le nombró el 10 de diciembre de 1511 capitán de campo en Italia. Cuando estaba mandando el asedio de la ciudad y castillo de Cologna (entre Lonato y Legnano) el 28 de mayo de 1513, fue herido por un arcabuz en el muslo derecho. Con el príncipe Rudolf de Anhalt mandó las tropas en Verona en el mismo año contra los venecianos, los cuales querían conquistar esta importantísima ciudad.

En julio de 1515 Wilhelm y Wolfgang von Rogendorf asistieron en Viena a la doble boda en la cual actuó el emperador Maximiliano I en lugar de Carlos $\mathrm{V}$ o el archiduque Fernando. Uno de los dos tenía que ser el marido de la novia, Ana de Hungría o Jagellón. Luis de Hungría en esta ocasión se casó con María, hija de Felipe el Hermoso y la reina Juana de Castilla ${ }^{5}$.

Rogendorf se convirtió en lugarteniente del joven Carlos $\mathrm{V}$ en Frisia en 1517 y al año siguiente en consejero secreto y mayordomo supremo del joven infante Fernando. Después de la muerte del emperador Maximiliano I los nietos y herederos de éste le nombraron el 27 de julio de 1519 comisario para encargarse de la lugartenencia interina en los países austriacos y para recibir el juramento en el nombre de los dos hermanos, Carlos y Fernando, junto al cardenal Mateus Lang, los obispos de Trento y Trieste, que eran Bernhard von Cles y Pietro Bonomo, Jacobo de Bannissis, Ciprian von Sernthein y otros. En 1520 fue enviado en una misión de los Países Bajos a Innsbruck.

El 11 de diciembre se casó Ana de Hungría con el archiduque Fernando en Innsbruck "per procuratorem" y fue Wilhelm quien representó al infante. La boda se celebró el 26 de mayo de 1521 en Linz.

Hasta esta fecha es significativo un recuento superficial de los bienes y honores recibidos de los Habsburgo. El 20 de febrero de 1506 recibió como feudo de Maximiliano por sus méritos y los de sus antepasados al servicio del rey Felipe y Maximiliano los bienes del difunto Georg von

\footnotetext{
${ }^{5}$ Hermann WIESFLECKER, Maximilian I. Die Fundamente des habsburgischen Weltreiches, Wien 1991, pp. 187 ss.
} 
Eckartsau. El 21 de marzo de 1506 Wilhelm firma una cédula hipotecaria a nombre del emperador Maximiliano por cinco mil florines para dos oficios en el señorío de Steyer. Los hermanos Wilhelm y Wolfgang, ambos consejeros imperiales, dan al emperador un préstamo por 20.000 florines, recibiendo como garantía el castillo y el señorío de Steyer y Hall. En 1513 reciben en feudo de parte del abad Sigmund de Melk la localidad de Gundersdorf y en 1521 le nombra administrador del señorío de Aggstein lo que confirma en 1530 Fernando I, concediéndole el usufructo del castillo de por vida. El 2 de mayo de 1515 se le concedía en Augsburgo la administración de Sankt Pölten y al año siguiente el Emperador le dio las entradas de la localidad de Wilhelmsburg durante toda su vida. El 3 de marzo de 1521 los hermanos Wilhelm, Wolfgang y Georg y sus descendientes legítimos fueron elevados por el emperador Carlos $\mathrm{V}$ a barones del Sacro Romano Imperio, mencionando de manera especial los méritos que Wilhelm había acumulado en el servicio del emperador Maximiliano y de su hijo el rey Felipe de Castilla, León y Granada, en el de Carlos V y su hermano Fernando, sirviendo en las campañas de guerra y en muchos otros negocios. El Emperador dio al castillo Pöggstall el nombre Rogendorf y liberó el castillo de toda forma de dependencia feudal y lo convirtió, con el castillo Mollenburg, en una baronía libre concediendo a Wilhelm como el mayor y a sus sucesores el derecho del juicio de sangre, como también los tesoros y minas de metal en todo su territorio, junto al derecho de acuñación. El 16 de octubre de 1521 el archiduque Fernando confirma a los hermanos Wolfgang y Georg el castillo de Pöggstall, ahora Rogendorf, con todas sus pertenencias.

Wilhelm se casó el 17 de septiembre de 1505 con Elisabeth, hija del conde Hans von Öttingen y de Elisabeth, última condesa y heredera del señorío de Condé en el Hennegau (Hainaut) con la cual llegó el 16 de julio de 1510 a Pöggstall. Murió el 31 de marzo de 1518 en Amberes.Tuvieron tres hijos: Christoph, Wolfgang y Georg. Al parecer contrajo segundas nupcias con Rosina, hija de Franz von Gastin, barón de Gamiels. Christoph renunció en Bruselas el 26 de julio de 1529 a sus derechos de heredero universal a favor de sus hermanos menores. Anna, la única hija, se casó en 1530 con Christoph barón de Eitzing, lugarteniente de Rogendorf en España, que junto con su hermano Erasmo, se unen a la lista de nobles de la Baja Austria que lucharon en la Península, con quien tuvo catorce hijos.

Mientras Bergmann es muy prolijo en la elaboración de sus datos cuando dispone de documentación a su alcance, cuando se refiere a la 
estancia de Rogendorf en España se ciñe a aspectos generales ${ }^{6}$. Según dice el emperador fue a España en barco, acompañado por Wilhelm von Rogendorf que era capitán supremo de campo sobre toda la infantería alemana. Luchó contra los moros, les venció y conquistó la montaña Spadon (sic) que el enemigo había fortificado y construyó, en 1522, un puente. Después hizo una incursión en Béarn, consiguió a través de un fuerte asedio la rendición de la fortaleza de Fuenterrabía ocupada por los franceses y se convirtió en lugarteniente de Cataluña, Rosellón y Cerdaña. El emperador le concedio el hábito de caballero de Calatrava y le nombró capitán de su guardia.

La presencia de Rogendorf en España y de un contingente de 4.000 alemanes tiene que ponerse en relación basicamente con una ayuda militar en la problemática frontera francesa y en el levantamiento de los moriscos valencianos ante la decisión de Carlos $\mathrm{V}$ de convertirles a la fuerza. Los moriscos rebeldes se refugiaron en la sierra de Espadán, y contra ellos fue enviado un ejército de 10.000 soldados, entre los cuales se encontraban los 4.000 soldados de Rogendorf, que fueron desde la frontera de Cataluña, donde estaban de guarnición ${ }^{7}$.

El Archivo General de Simancas conserva documentación que permite trazar los movimientos de Wilhelm von Rogendorf en la Península durante su estancia de 1522 a $1528^{8}$. Rogendorf al parecer viajó desde los Países Bajos junto con el Emperador, haciendo escala en Inglaterra, donde éste permaneció desde fines de mayo de 1522 al 6 de julio. Se embarcó en Southampton el 6 de julio, navegando del 7 al 15 de dicho mes y llegando a Santander el 16 de julio. La fecha de 1522 para referirse al primer año de estancia de Rogendorf en España nos parece verosímil, pues es a partir de este año cuando empieza a figurar en las cuentas de "Pagas de caballeros y

\footnotetext{
${ }^{6}$ BeRgManN, Über die Freiherren, p. 546.

${ }^{7}$ Manuel FernáNDez Álvarez, La España del emperador Carlos V (1500-1558. 1517-1556), "Historia de España Menéndez Pidal", XX, dir. por José María Jover ZAMORA", Madrid 1990, p. 312.

${ }^{8}$ AGS, CjH. Años 1369 a 1574. Rochendorff. Capitán General de los alemanes. Cuentas y quitaciones, legajo 9: 6-13 Relación de la gente de guardas del reino con el dinero que montan. Quitaciones de continos.- Acostamientos y tenencias.- Pagas de caballeros y capitanes. 1522-1526. Ibidem legajo 10: 64-89 Cuentas y quitaciones de Rochendorff, Capitán General de los alemanes, de gastos efectuados en Rosellón y cartas de pago a vecinos de Perpignan por préstamos para dichos gastos. 1525-1526.- Ibidem, Galeras, legajo 216, 1525-1526. Cartas cruzadas con Martín de Adurça "pagador de los alemanes" que estaban en Levante esperando las pagas adeudadas.
} 
capitanes". También es muy posible que participase en el asedio a la fortaleza de Fuenterrabía en 1524. Fuenterrabía, tomada por los franceses en 1522, era la llave para Navarra y Castilla, por lo que el Emperador puso su máximo empeño en recuperarla, lo que logró, en una de sus más brillantes empresas militares, en febrero de 1524. Quizás como consecuencia de haberse distinguido en la toma de esta vital plaza fuerte Rogendorf se hizo acreedor al hábito de Calatrava y a la encomienda de Otos. Seguramente podemos poner en relación también la concesión de estos honores con su capacidad de reunir el contingente nada despreciable para la época de 4.000 soldados, y compararlo con otros casos similares como el de Pedro Ohmuchievich a quien se concedió hábito de Santiago en 1596, por mucho menos9.

La cédula de Carlos $\mathrm{V}$ otorgando hábito de Calatrava a Rogendorf es de 27 de abril de 1524, cuando el emperador al parecer se hallaba en una localidad cerca de Burgos ${ }^{10}$. En los sólo dos folios que se han conservado sobre la información hecha para su entrada en la Orden, aparecen tres testigos ${ }^{11}$. Fue realizada en Burgos el 26 de abril de 1524 por el capellán Sebastián de Mera. En el interrogatorio a los testigos se observa su carácter rutinario y esquemático, típico de estos primeros años del siglo XVI. Uno de ellos, el doctor Brandauer, podría pertenecer al séquito de Rogendorf, lo que quizás esté a indicar que Rogendorf estaba junto al Emperador por estas fechas. Carlos V, desde Valladolid el 12 de agosto del mismo año, dio licencia a Rogendorf, que en ese momento estaba en aprobación para caballero en el Convento de Calatrava la Nueva, para que pudiese ir a la guerra contra Francia y gobernase a los alemanes de los que era capitán y que se le tuviese presente el tiempo que allí sirviese ${ }^{12}$. Así pues la intervención de Rogendorf en Francia puede verse en el marco más general de la

\footnotetext{
${ }^{9} \mathrm{AHN}$, OM, Santiago, expediente 5856. Originario de Bosnia y Macedonia, en esos momentos ocupadas por los turcos, había puesto al servicio de Felipe II doce galeones atracados en el puerto de Lisboa, con una tripulación de 1.500 hombres.

${ }^{10}$ Manuel de Foronda y Aguilera, Estancias y viajes del Emperador Carlos V, desde el día de su nacimiento hasta el de su muerte; comprobados y corroborados con documentos originales, relaciones auténticas, manuscritos de su época y otras obras existentes en los archivos y bibliotecas públicos y particulares de España y del extranjero, Madrid, 1914, p. 236. Foronda sugiere que podría tratarse de San Pedro Samuel o San Pedro del Val, ambas localidades en la provincia de Burgos.

"AHN, OM, Calatrava, expediente 2226 bis.

${ }^{12}$ FORONDA, Estancias, p. 241.
} 
ofensiva de las tropas imperiales que había empezado en abril de 1524 para la conquista de Provenza y la toma de Marsella. Sólo se consiguió conquistar Tolón, y esta conquista también fue infructuosa porque Francisco I decidió aprovechar el momento para reconquistar el Milanesado y hubo que ordenar la retirada. Los reveses de las armas imperiales finalizaron con la victoria de Pavía el 24 de febrero de $1525^{13}$.

Rogendorf conquistó lugares cercanos a Perpignan como Saint Paul, Rocquefort, Palme, donde quedaron estacionadas las tropas alemanas, aunque pocos meses después cayeron otra vez en manos francesas, obligando a los alemanes a la retirada hacia el Sur.

La permanencia de un año en la fortaleza de Calatrava se consideraba excesivamente larga y se fue perfilando un período más reducido de tiempo que se fijó en tres meses, dejando transcurrir una año desde la recepción del hábito hasta la ceremonia de la profesión. También se procedió a acortar la estancia en el Convento a cambio de servicios militares, lo que sería el caso de Rogendorf ${ }^{14}$. Efectivamente su cédula de profesión está fechada en Toledo el 3 de noviembre de $1525^{15}$.

En realidad la concesión de encomiendas a extranjeros era un tema muy delicado que ya en las Cortes de Valladolid de 1518 había provocado las protestas de los castellanos, que solicitaron que se les excluyese de ellas. Pero las necesidades de Carlos $\mathrm{V}$ fueron en algunos casos más fuertes que la opinión popular ${ }^{16}$. Por este motivo aparece aún más notable la concesión a Rogendorf de la encomienda en un clima adverso ${ }^{17}$. Emma Solano la ha descrito en un período muy cercano al año de concesión a Rogendorf ${ }^{18}$. La parte más significativa era el pueblo de Borox, donde se hallaba la residencia principal del comendador. Situado entre Aranjuez e Illescas, Borox estaba en poder de la Orden de Calatrava desde 1191 junto con el castillo de Dueñas, la mitad de Mocejón y un horno y molino en Toledo. La casa de la encomienda en Borox tenía una torre, bodega, caballeriza, corral y horno.

\footnotetext{
${ }^{13}$ Fernández Álvarez, Carlos $V$, pp. 361-369.

${ }^{14}$ FERNÁNDEZ, La Orden, p. 94.

${ }^{15}$ FORONDA, Estancias, p. 262.

${ }^{16}$ Joseph PÉREZ, La revolución de las Comunidades de Castilla (1520-1521), Madrid, 1985, p. 119.

${ }^{17}$ FERnÁNDEZ, La Orden, p. 95.

${ }^{18}$ Emma Solano, La Orden de Calatrava en el siglo XV. Los señoríos castellanos de la Orden al fin de la Edad Media, Sevilla, 1978, pp. 247-250.
} 
El tributo de terrazgo suponía anualmente 700 fanegas de pan y 1.000 arrobas de vino. En Ciruelos había otra "casa fuerte" y pertenecía a la Orden desde 1176 en que Alfonso VIII se la concedió. Es de destacar el hecho de que aquí se hallase sepultado el fundador de la Orden, Raimundo de Fitero, en su iglesia. Entre otras propiedades se encontrabà también la dehesa de Otos, que daba nombre a la encomienda, que lindaba con la ribera del Tajo y los términos de Yepes, Ciruelos, Ocaña y Aranjuez. Otras dos dehesas eran las de la Alhóndiga, con la salina de Abejarejos, y la de la Higuera. La encomienda de Otos era una de las más valiosas de la Orden, y el comendador disponía anualmente, hacia 1493, de 850.000 maravedíes. Podemos suponer que Rogendorf visitó estos lugares en su estancia en España, aunque no debió residir nunca en ellos como exigían los estatutos de la Orden. Cuando partió de la Península no tenemos noticia de que volviese nunca, por lo que se planteaban dos problemas: el del absentismo del comendador de su encomienda, habitual en estos años, y las vías por las cuales el dinero llegaba a manos de Rogendorf en Austria. Para años posteriores tenemos el ejemplo de cómo Wolf Rumpf, caballero de Santiago y comendador de Paracuellos, recibía en Austria el dinero procedente de su encomienda ${ }^{19}$.

$\mathrm{Al}$ menos disfrutó de ella hasta 1536 y para establecer esta fecha nos basamos en la existencia de una moneda de la que conocemos dos ejemplares: uno se encuentra en el Museo de Pöggstall y el otro en el Museo de Bellas Artes de Viena. Es de plata, tiene un diámetro de $33 \mathrm{~mm}$ y un peso de 17 gramos. El anverso muestra un busto de Rogendorf del lado izquierdo con cabello corto y larga barba. La inscripción es como sigue: GVILL.LIB.BARO.EX:ROGENDORF.COMEN.DE.OTOS.AETA.LV, debajo del hombro está la cifra 1536. En el reverso de la medalla se puede ver una alabarda entrecruzada con un martillo de combate; en los campos entre estas dos armas en la parte superior aparece la cruz de caballero de Calatrava, a la izquierda el escudo de los Rogendorf, a la derecha el escudo de los Wildhaus

\footnotetext{
${ }^{19}$ Friedrich EDELMAYER, "Manus manum lavat". Freiherr Wolf Rumpf zum Wielross und Spanien, "Die Fürstenberg. 800 Jahre Herrschaft und Kultur in Mitteleuropa", ed. Erwein H. ElTZ, Arno STROHMEYER, Korneuburg 1994, p. 243. El procedimiento era el siguiente: el embajador imperial Khevenhüller daba en metálico este dinero en Madrid en el banco de Antonio Vázquez Vuelta a los banqueros genoveses Sinibaldo Fiesco y Juan Baptista Justiniano. Estos emitían una letra de cambio a nombre de Juan Pedro Cataneo Serra y Juan Benito Spinola en Placencia. Allí debía recibir el dinero en metálico un procurador o los banqueros de los Fugger Hieronimus y Christoph Otten y transmitirlo a Rumpf. En la versión española de este artículo se omite este párrafo: "Wolf Rumpf de Wielross y la España de Felipe II y Felipe III", "Pedralbes", 16 (1996) pp.133-163.
} 
y en la parte inferior una coraza, rodeado todo por una guirnalda de palma ${ }^{20}$. (Véase Figura 1, al final del artículo).

De sus cargos en España él mismo nos hace relación al pedir sus emolumentos atrasados. Se le debían un año de su cargo de capitán de la guardia, tres meses de su paga de capitán general de los alemanes en Cartagena y cantidades de la ayuda de costa de su cargo de capitán general de la frontera de Francia en Perpignan. Hace relación de estos atrasos el 23 de octubre de 1527 desde Bilbao ${ }^{21}$. Otro títulos que recibe es el de capitán general de los condados de Rosellón y Cerdaña ${ }^{22}$ y los de consejero y chambelán del Emperador ${ }^{23}$. A fines de septiembre de 1525 Rogendorf se traslada junto con el gentilhombre del Emperador, Charles Vanderaa, y otros gentilhombres desde Perpignan a Toledo, donde se encontraba Carlos V. Este desplazamiento se hizo "en poste", es decir a caballo, cambiando de montura en las diferentes estaciones preparadas para ello. Este viaje supuso la ausencia de Rogendorf de Perpignan del 23 de septiembre de 1525 al 9 de agosto de 1526, período en que sus lugartenientes llevaron las cuentas de gastos. Durante estos meses Rogendorf estuvo casi seguramente al lado del Emperador y Francés de Zúñiga pudo observarle a sus anchas y transmitir sus impresiones a la posteridad. De esta manera Rogendorf debió conocer ciudades españolas como Toledo, Aranjuez, Madrid, Sevilla, Córdoba, Granada. El viaje de Perpignan a Toledo costó 151 ducados de oro y 136 maravedíes ${ }^{24}$. En julio de 1526 Rogendorf va de Granada a Valencia con 15.000 ducados para los alemanes allí estacionados ${ }^{25}$, y en agosto de Valencia a la sierra de Espadán para visitarla, gastando 16 ducados $^{26}$.

Francés de Zúñiga nos brinda estos preciosos datos sobre Rogendorf, en su peculiar estilo, refiriéndose al año 1526: "En estos tiempos, en el reyno de Valencia, quando las alteraciones de España, fueron convertidos a

\footnotetext{
${ }^{20}$ Josef BERGMANN, Medaillen auf berühmte und ausgezeichnete Männer des österreichischen Kaiserstaates, I, Wien, 1844, p. 219.

${ }^{21} \mathrm{AGS}, \mathrm{CjH}$ 12-189.

${ }^{22} \mathrm{AGS}, \mathrm{CjH} 10-89$.

${ }^{23} \mathrm{AGS}, \mathrm{CjH} .10-67$. Parties extraordinaires desbourssées par le seigneur de Roghendorff depuis le XXIX jour de septembre 1525 jusques et y compris le XXI jour doctobre 1526 .

${ }^{24}$ Ibídem.

${ }^{25} \mathrm{AGS}, \mathrm{CjH}$ 10-69. Compte que rend Regnault Bormann des deners quil a paye et desboursse pour les affaires de le empereur au nom de monseigneur de Roghendorff.

${ }^{26}$ Ibidem
} 
la fe católica muchos moros del dicho reyno; y dende a pocos días, como sea gente liviana y de seta necia sin fundamento, muchos dellos se levantaron y se fueron para la sierra con sus mugeres e hijos. Se hizieron fuertes y de cada día yvarł para ellos muchos moros del dicho reyno. Y como fue sabido por el Emperador, embió religiosos de buena vida y tales personas a les requerir que se bolviesen y reduziesen a la fe católica y biviesen en Dios y en sus casas, que les perdonava lo pasado. Y como los duros que han de ser perdidos no les pueden escusar, en nada de lo dicho quisieron venir.Y la Católica Magestad mandó a un cavallero alemán muy onrado, que avía por nombre Rocandolfo, el qual parecía tío de Josephe o al embaxador de Rusia o al comendador Herrera, alcayde de Panplona (que parecía odrero en Madrigal rezién casado o hoste de correos ynglés) y a don Beltrán de Robles, el qual parecía galgo que a poder de golpes salió por albañar, lo[s] quales hizieron cosas tan señaladas en esta g[u]erra de los moros que a Dios hizieron servicio y a Su Magestad no menos.Y este don Beltrán de Robles, como a este real llegase, hizo cinco casas en el desierto; y llevó al real este don Beltrán siete cofres más vazíos que Role quando sale de dolencia. Y este don Beltrán, [si] las casas que en este mundo edificó las tuviera juntas, más población tuviera qu'El Cayro es. Y como deste viaje llegase, sus necesidades remedió el muy alto Emperador; y los moriscos de Granada le tiñeron las barbas porque venía cano"27.

Firma unas cuentas de gastos de sus lugartenientes en Cartagena el 21 de octubre de 1526, entre los que aparece Christoph de Eitzing quien en 1530 se casará con su hija Anna.

En octubre de 1527, como hemos visto, se encontraba en Bilbao reclamando sus pagas atrasadas, además de unos dineros de don Beltrán, probablemente Beltrán de Robles, "...de los dineros de don Beltrán si su Magestat mandara proveerme en ello como en los otros visto como y quan claramente se me deve no fuera mucho mas pues su dicha Magestat ansi lo quiere lo qual dize que mandara ver y averiguar". Todo el dinero correspondiente a estos pagos el pagador de los alemanes, Martín de Adurça, debía efectuarlos a micer Enrique Ynper. Al año siguiente, el 3 de enero de 1528, encontrándose en las posesiones de su primera mujer en Condé, pocos días después de haberse embarcado en Bilbao, agradece al Emperador que acceda

\footnotetext{
${ }^{27}$ Francés de ZúÑIGA, Crónica burlesca del Emperador Carlos $V$, Ed. por José Antonio SÁNCHEZ PASO, Salamanca, 1989.
} 
a todas sus solicitudes: "...que es que los dineros que se perdieron corriendo la posta manda [el Emperador] que se me pagen y asimismo manda que de la guarda se me pagen y tanbien los tres meses que se me quedaron a dever de mis pajas de capitan general de los alemanes en Cartajena manda que se me pagen y tanbien dize su dicha Magestat que en lo de los dineros de don Beltrán mandara que se me haga justicia y breve lo hara de terminar y asi mismo proveerme dello y en lo de la ayuda de costa de mi cargo de capitán general de la frontera de Francia en Perpignan dize su dicha magestat que ansi mismo me mandara breve proveer y rreconpensar dello"28. Habiendo fallecido Martín de Adurça dirige la misiva a su hermano Juan, que está en la corte y que es argentier del Emperador.

Entre los diversos gastos de los que ha quedado constancia en las cuentas llevadas por sus lugartenientes en su ausencia, se encuentra uno muy curioso: el 22 de noviembre de 1525 se compró por cuatro ducados una red para la pesca de truchas que Carlos V había pedido a Rogendorf ${ }^{29}$. Este encargo del Emperador sugiere una confianza entre los dos hombres, quizás conversaciones a este propósito o incluso el haber pescado juntos en alguna ocasión. El interés por la pesca tenía una larga tradición en la familia Habsburgo y ya el abuelo de Carlos V, Maximiliano I, había hecho componer en 1504 a Wolfgang Hohenleitner un libro ilustrado sobre este tema $^{30}$. En la autobiografía ilustrada de Maximiliano I (Weisskunig) se puede ver también una escena en la que aparece éste con una caña en las manos, rodeado de algunos personajes con diferentes objetos relacionados con la pesca. $\mathrm{Al}$ fondo puede apreciarse como desde unas barcas se faena con unas pequeñas redes ${ }^{31}$.

También estas cuentas nos permiten establecer en líneas generales los movimientos de las tropas alemanas de Rogendorf, permanentemente necesitadas de dinero. Esta acuciante necesidad de dinero en metálico se solucionó pidiendo préstamos a diferentes mercaderes de Perpignan, de lo

\footnotetext{
${ }^{28} \mathrm{AGS}, \mathrm{CjH} 10-68$.

${ }^{29} \mathrm{AGS}, \mathrm{CjH} 10-64$. Compte de lextraordinaire fait par Christofer Seigneur de Eyzing en labsence de monseigneur de Roghendorff.

${ }^{30}$ Biblioteca Nacional Austriaca, (Österreichische Nationalbibliothek), Handschriftensammlung, Codex Vindobonensis 7962, Tiroler Fischereibuch. 61 ff., papel y pergamino, $320 \times 220$.

${ }^{31}$ Kaiser Maximilians I. Weisskunig, ed. por H.Th. MUSPER, Rudolf BUCHNER, Heinz-Otto Burger y Erwin PetermanN, II, Stuttgart, 1956, p. 43.
} 
que ha quedado testimonio cuando estas cantidades fueron devueltas en $1528^{32}$ : 300 ducados de oro (112.500 maravedis) a Vernaldo Alberto, vecino de Perpignan; 200 ducados a Juan Antonio Sánchez; 224 ducados de oro a los consules y a Rafael Masdemont, también de Perpignan, 40 ducados a Bernat Sancho. Los alemanes se mantenían en contacto continuamente con el Emperador y con su capitán, de ahí los numerosos viajes de ida y vuelta a donde se encontraba la corte: en noviembre de 1525 Erasmo de Eitzing, hermano de Christoph, viaja desde Perpignan a la Corte de Carlos V, en este momento en Toledo, para recibir instrucciones del Emperador sobre lo que hacer con los lugares ganados por Rogendorf, ya que la tregua se termina$\mathrm{ba}^{33}$; Jean Popre, gentilhombre alemán, yendo a la corte para resolver asuntos relativos al pago de los alemanes encontró la muerte entre Perpignan y Barcelona de un tiro de ballesta de unos bandoleros por lo que Christoph Regel, alemán, fue enviado para recoger las cartas que llevaba Popre ${ }^{34}$. En diciembre de 1525 Roelf van Marmoets, que a pesar de su nombre flamenco viene denominado "gentilhombre alemán", va al Emperador para tratar sobre el pago a las tropas ${ }^{35}$ y el alguacil Andrés Roca lleva algunos prisioneros desde Perpignan a Toledo ${ }^{36}$. Uno de los más viajeros es Gilles Hachinger que gasta 54 ducados de oro para ir de Perpignan a Toledo y de Toledo a Talavera el 24 de diciembre de 1525 , volviendo de Toledo a Perpignan el 17 de marzo de $1526^{37}$. El primero de enero de 1526 viaja hacia el Emperador para advertile que los lugares ganados por Rogendorf habían sido tomados por los franceses ${ }^{38}$, y el día 7 del mismo mes el secretario Michel Gilles hace lo mismo para tratar con Carlos $\mathrm{V}$ asuntos a su requerimiento ${ }^{39}$.

Una vez los alemanes se encontraron en Castellón y Valencia continúan los viajes desde estas ciudades para conferenciar con Carlos V y

\footnotetext{
${ }^{32} \mathrm{AGS}, \mathrm{CjH}$ 10-81-85. La primera carta de pago lleva el siguiente título: Carta de pago e finequito para el thesorero Johan de Adurça, mi señor. De los trezientos ducados doro que en nombre del capitan e comendador Roquendolf se pago a Vernaldo Alberto, vecino de Perpignan. En las siguientes cambia sólo el nombre.

${ }^{33} \mathrm{AGS}, \mathrm{CjH} 10-64$.

${ }^{34}$ Ibidem.

${ }^{35}$ Ibidem.

${ }^{36}$ AGS, CjH 10-67.

${ }^{37}$ Ibidem.

${ }^{38} \mathrm{AGS}, \mathrm{CjH} 10-64$.

${ }^{39}$ Ibidem.
} 
con Rogendorf. François de Thaffardont el 1 de septiembre de 1526 va de Castellón a Granada y el 19 del mismo mes de Valencia a Granada ${ }^{40}$. El llamado "bastard de Nassou" se traslada de Valencia a Granada ${ }^{41}$.

Otro de los destinos de estas misiones son los viajes a Barcelona para ir a encontrar al pagador Martín de Adurça o, en menor medida, al Virrey para tratar asuntos relacionados con las tropas. El Virrey de Cataluña manda cartas a Beltrán de Robles que está en Castellón el 8 de mayo de $1526^{42}$.

Las cuentas también proporcionan noticias sobre los productos que se compraban para abastecer a los soldados alemanes que custodiaban los lugares conquistados, gastos que corrían a cargo del Emperador. Como material bélico se cita pólvora, balas de cañón y plomo llevados a los lugares de Saint Jacques, la Palme y Rocquefort ${ }^{43}$. El capitán Berlingher realizó transportes de pólvora y munición hasta Saint Jacques ${ }^{44}$. Otro apartado fundamental es el de los alimentos en el que las partidas más importantes están constituidas por la compra de cerdos, bueyes y trigo. A veces, estas actividades daban lugar a episodios curiosos, según el alternarse de los avatares de la guerra, como es el caso de la compra de trece cerdos para el avituallamento de las tropas estacionadas en el lugar de Saint Paul, que una vez caído en manos francesas supuso también la pérdida de los preciados animales. O la compra de cuatro bueyes que siendo llevados a Saint Paul se escaparon por las montañas. Uno de ellos nunca fue recuperado y los otros tres, una vez tomado el lugar por los franceses, tuvieron que ser vendidos. También se llevaron cinco bueyes a Palme y Saint Jacques. Dos o tres días después estos lugares cayeron en manos francesas junto con la carne. Para conseguir pan se compraba trigo que se molía, o bien en los mismos lugares ocupados -en Palme se debió proceder a la reparación del molino destruido por los franceses-, o en Perpignan. La harina, habiendo sido tomado el lugar de Saint Paul no fue más allá de Estagel y hubo que devolverla a Perpignan. El hecho de deber moler la harina comportaba también el alquiler

\footnotetext{
${ }^{40} \mathrm{AGS}, \mathrm{CjH} 10-67$.

${ }^{41} \mathrm{AGS}, \mathrm{CjH} 10-69$.

${ }^{42} 42377 \mathrm{AGS}, \mathrm{CjH} 10-64$.

${ }^{43} \mathrm{AGS}, \mathrm{CjH}$ 10-70. Compte que rend le seigneur de Wilderstorff lieutenen de monsigneur de Roghendorff.

${ }^{44} \mathrm{AGS}, \mathrm{CjH} 10-64$
} 
de sacos, que perdidos como el resto de productos, debían ser abonados a sus propietarios ${ }^{45}$.

La presión francesa provocó el desplazamiento de las tropas alemanas desde estas localidades hacia el Sur, al parecer parte de ellas se estacionaron en Camprodón. Los enfermos fueron trasladados a Colliure y en naves fueron transportados de Colliure a Barcelona y Valencia ${ }^{46}$. Sabemos también que los alemanes heridos y enfermos fueron llevados aparte desde la sierra de Espadán a Cartagena para que no supusieran un retraso para el resto de los soldados ${ }^{47}$. Las tropas finalmente pasaron de Cartagena a Italia ${ }^{48}$.

Además de los honores y recompensas económicas citadas, Carlos $\mathrm{V}$ al parecer regaló a Rogendorf, durante su estancia en España, una famosa armadura que hoy se encuentra en la armería del Museo de Bellas Artes de Viena. Fue fabricada por Kolman Helmschmid en Augsburgo en $1525^{49}$. (Véase Figura 2, al final del artículo). Es opinión generalizada que esta armadura en forma de traje para infante es el más bello ejemplar conservado de este tipo, y mucho dice sobre la consideración de Carlos $\mathrm{V}$ hacia los méritos de Rogendorf. Jacob Schrenck inmortalizó al famoso propietario de la coraza en su obra ${ }^{50}$. Una copia italiana de este tipo de armadura-vestido la da Angelo Bronzino en su retrato de 1531/32 de Guidobaldo I della Rovere, duque de Urbino, que se halla en Florencia en Palazzo Pitti.

Las últimas noticias que tenemos de Rogendorf en España nos lo muestran en Bilbao a últimos de diciembre de 1527, como hemos dicho, a punto de embarcarse hacia Condé, dejando probablemente la Península para siempre. Con seguridad sabemos que en el otoño de 1529 Rogendorf estaba

\footnotetext{
${ }^{45}$ Ibídem.

${ }^{46} \mathrm{AGS}, \mathrm{CjH} 10-70$.

${ }^{47} \mathrm{AGS}, \mathrm{CjH} 10-67$.

${ }^{48} \mathrm{AGS}, \mathrm{CjH} 10-70$.

${ }^{49}$ Hofjagd- und Rüstkammer A 374. Véase Ortwin GAMBER, Kolman Helmschmid, Ferdinand I. und das Thun'sche Skizzenbuch 9-38, "Jahrbuch der Kunsthistorischen Sammlungen in Wien", 71 (1975), p.32.- Bruno ThOMAS y Ortwin GAMBER, Katalog der Leibrüstkammer, I, Viena, 1976, pp. 227-228.- Roberto CAPUCCI, Roben wie Rüstungen. Mode in Stahl und Seide einst und heute. Catálogo de exposición. Neue Burg. Hofjagd und Rüstkammer. Kunsthistorisches Museum Wien. Viena, 1991, n. 55, p. 132.

${ }^{50}$ Jacob SCHRENCK VON NOTZING, Bildinventar der Ambraser Heldenrüstkammer, ed. en latín Innsbruck, 1601, grabado 81. En 1603 apareció una versión alemana de este trabajo, también en Innsbruck.
} 
de vuelta en Austria, ocupado en la nada convencional tarea de defender Viena del peligroso ataque turco de este año, junto a su cuñado Niklas de Salm, que moriría al año siguiente como consecuencia de las heridas recibidas durante el asedio. En 1530 fue a la Dieta de Augsburgo como mayordomo mayor de Fernando I, entre cuyos consejeros se encontraban Sigmund barón de Dietrichstein, Niklas conde de Salm el joven, Marc Sittich von Ems, quienes tenían a miembros de su familia o séquito en las Ordenes Militares españolas. También estuvo presente el hijo de Rogendorf, Christoph. Fernando I, en 1539 le concedió a Rogendorf y sus descendientes la función de camarero hereditario de Baja Austria. Se retiró de la corte a su castillo de Gundersdorf, pero de nuevo fue llamado a las armas el 3 de enero de 1541 como comandante general en Hungría. Contando sesenta años era demasiado anciano para esta acción, por lo que cedió a su hijo Christoph la posibilidad de ganar la honra de una victoria militar, confiándole el asalto a la ciudad de Ofen. La acción constituyó un fracaso y Rogendorf que había permanecido en el campamento fue herido gravemente en un brazo, como narra con todos los pormenores Bergmann. En la noche del 21 al 22 de agosto de 1541 atravesó el Danubio hacia la ribera de Pest, mientras el ejército era dispersado por una tormenta. Rogendorf fue llevado por su médico y por su camarero en una barca y trasladado a la isla de Shütt, cerca de Pressburg. Murió en Somerein y su cuerpo fue llevado a Pöggstall y colocado en la iglesia del castillo, aunque actualmente se desconoce el emplazamiento exacto de su tumba.

Según Bergmann Carlos V permitió a su hijo Christoph "decorar su pecho" con la cruz de Calatrava que llevaba su padre para recompensarle por haberle relevado en el asedio de Ofen en el verano de 1541 , lo que no sabemos si significa que le concedió el hábito de Calatrava y le sucediese en la encomienda de Otos.

A causa de no haber hecho Wilhelm von Rogendorf inventario de sus bienes de la encomienda, Carlos V ordenó que se cobrasen algunos de ellos para sí, escribiendo a este efecto a Maximiliano II y María, que en estos años ejercían la lugartenencia en España, el 25 de enero de 1550 desde Bruselas: "Al Consejo de Hórdenes. Por la relaçión que va con ésta entenderéys lo que passa en lo que toca a algunos bienes que dexó Rocaldolfo y nos pertenesçen por no haver hecho inventario dellos al tiempo de su muerte, conforme a las constituçiones de su Horden y çiertos lugares que teníamos del Conde, su hijo, en estas tierras de Flandes se han ya vendido y lo mesmo creemos havrá hecho el serenísimo rey de Romanos, nuestro 
hermano, de lo que tienen en sus tierras; y por esto será bien que los que en essos reynos se hallaren del dicho Rocandolfo se cobren para Nos, y assí mandaréys a los del Consejo de las Ordenes que entiendan con diligencia en ello"51.

La iconografía de Wilhelm von Rogendorf se enriquece con otros dos testimonios, a parte de la moneda ya citada. Otra representación suya, de sus hermanos Georg y Wolfgang, y de la esposa del primero, Elisabeth von Öttingen, se encuentra en el libro de retratos de Hieronymus Beck von Leopoldsdorf $^{52}$. Aquí aparece de una manera que quizás, según interpreta algún especialista, pudo tratarse de la parte derecha de un díptico como sugiere la posición de las manos. (Véase Figura 3, al final del artículo). La parte izquierda debió ser una virgen. El propietario del original fue Seyfred Breuner, camarero de Rodolfo II y su consejero secreto. Los retratos de los Rogendorf debieron proceder de la colección de su esposa Elisabeth von Eitzing, hija de Christoph von Eitzing, quien fuera lugarteniente de Rogendorf en España y de Anna von Rogendorf, por lado materno una nieta de Wilhelm von Rogendorf y de Elisabeth von Öttingen. La vestimenta de los retratados, nobles de la Baja Austria, tienen unas características europeas lo que demuestra lo estrecho de los límites del archiducado. Esta tendencia se da también en la segunda mitad del siglo XVI, mientras se produce la primacía de la moda española ${ }^{53}$.

Otro retrato está en la galería de cuadros del Museo de Bellas Artes de Viena que posee un retrato oval donde está escrito el nombre "Wilhelm von Rogendorf" (1580, madera, 29 x $24 \mathrm{~cm}$, actualmente en la colección del Museo de Bellas Artes de Viena mostrada en el castillo de Ambras), en el que Rogendorf tiene los cabellos blancos y larga barba ${ }^{54}$ (Véase Figura 4, al final del artículo). También aparece representado al lado de otros caballeros en el famoso libro ilustrado de Maximiliano I sobre el arte del torneo y las fiestas cortesanas, el llamado "Freydal", custodiado actualmente en la armería del Museo de Bellas Artes de Viena, aunque esconde su rostro

\footnotetext{
${ }^{51}$ FERnÁNDEZ, La Orden, p. 127.

${ }^{52}$ Günther HeInZ, Das Porträtbuch des Hieronymus Beck von Leopoldsdorf, "Jahrbuch der Kunsthistorischen Sammlungen in Wien", 71 (1975), pp. 274, 275, 284, 286.

${ }^{53}$ Adel im Wandel. Politik. Kultur. Konfession 1500-1700, Catálogo de exposición, Rosenburg, 1990, pp. 171-172.

${ }^{54}$ Ovalbildserie zur Ambraser Rüstkammer: Wilhelm von Roggendorf. Museo de Bellas Artes, Viena, Castillo de Ambras, Gemäldegalerie Inv. Nr. GG 63.
} 
detrás de un velo negro en el transcurso de un baile de máscaras ${ }^{55}$. (Véase Figura 5, al final del artículo).

Rogendorf es citado brevemente una segunda vez en la "Crónica burlesca" de Francés de Zúñiga, lo que indica el relieve de este personaje, teniendo en cuenta que hay hechos y personas de gran envergadura que pasan sin ser advertidos en ella y su antipatía manifiesta por los extranjeros: "...Salinas, vuestro enbaxador, es buen caballero, deseoso de tener de comer como Francisco Gutiérrez, de manera quel gran espadarte tiene el dicho vuestro enbaxador en su posada hacha y media sienpre sobrada, y una mona en la bentana; y trae ropa de tafetán en día de apóstoles, y en otras fiestas ropa de jamelote. Paresce benesciano que saca agua ardiente para Rocandolfo, alemán"56. Estas frases podrían indicar que el embajador Salinas tenía un aspecto adusto y arrogante, como seguramente lo tendría un veneciano - a los que Rogendorf con tanto éxito había combatido- si hubiera tenido que servirle una bebida. Esta segunda cita confirma el respeto con que aparece tratado en una Crónica de estas características y en la que se valora primordialmente su personalidad de hombre de $\operatorname{armas}^{57}$.

Wilhelm von Rogendorf a lo largo de su vida estuvo al servicio de los Habsburgo, sobre todo en los campos de batalla de Europa, siguiendo el ejemplo de Carlos V, quien le protegió y honró por sus servicios. Como caballero de Calatrava luchó contra los musulmanes en la Península o contra los turcos en Hungría y este aspecto le da aún características medievales, muy parecidas a las necesidades que originaron la aparición de esta Orden en España. Entre arcaico y precursor de la presencia de las Ordenes Militares españolas en Austria, Rogendorf constituyó el núcleo inicial de un grupo de nobles, que al margen de su origen familiar, en muchos casos protestante, eligieron los hábitos españoles como una manera de exteriorizar sus actitudes vitales. Su ideología católica y pro hispánica hizo su fortuna en la corte austriaca en tiempos inciertos y supuso el paso de la lucha de la Orden de Calatrava contra los musulmanes en la Península, típica del período medieval, a la lucha contra los protestantes en Centroeuropa de la

\footnotetext{
${ }^{55}$ Inv. nr. K 5073 fol. 4r. Véase Quirin von LEITNER, Freydal. Des Kaisers Maximilian I. Turniere und Mummereien, Wien, 1880-1882, p. XCIV.

${ }^{56}$ ZúÑIGA, Crónica, p. 148.

${ }^{57}$ Este porte disgustado asociado a los venecianos es usado en otra ocasión en la Crónica: "paresció veneciano que se le anegó una carraca en Barcelona", p. 141.
} 
época moderna, en un ámbito exclusivamente aristocrático, contribuyendo a la creación de bases ideológicas que legitimaban el uso de las armas ${ }^{58}$.

ESTANCIA DE ROGENDORF EN ESPAÑA (1522-1528)

$\begin{array}{lll}16 \text { julio } & 1522 & \text { Santander } \\ \text { febrero } & 1524 & \text { Fuenterrabía } \\ 27 \text { abril } & 1524 & \text { Burgos } \\ \text { Verano } & 1524 & \text { Calatrava la Nueva } \\ \text { septiembre } & 1524 & \text { Va a Perpignan } \\ \text { septiembre } & 1525 & \text { Va de Perpignan a Toledo } \\ 23 \text { septiembre } & 1525 & \\ \text { a } 9 \text { de agosto } & 1526 & \text { En la corte } \\ \text { julio } & 1526 & \text { Granada a Valencia } \\ \text { agosto } & 1526 & \text { Valencia a la Sierra Espa- } \\ \text { dán } \\ \text { 21 octubre } & 1526 & \text { Cartagena } \\ \text { octubre } & 1527 & \text { Bilbao } \\ \text { diciembre } & 1527 & \text { Bilbao }\end{array}$

\footnotetext{
${ }^{58}$ Anna MUR RAURELl, Austríacos en las Órdenes Militares españolas en el siglo XVI, "Spanien und Österreich in der Renaissance. Akten des fünften Spanisch-Österreichischen Symposions, 21.-25. September 1987 in Wien" ed. W. KRÖMER, Innsbruck 1989 (=Innsbrucker Beiträge zur Kulturwissenschaft, Sonderheft 66), pp. 81-95. Una versión catalana del artículo apareció bajo el título: Austríacs dins els ordes militars espanyoles en el segle XVI, "Pedralbes" 9 (1989), pp. 15-35.- EADEM, El caballero barroco en España y Austria. "Honores de hábitos, tusones y ofizios", "Barroco español y austríaco, fiesta y teatro en la Corte de los Habsburgo y de los Austrias". Catálogo de exposición, Museo Municipal de Madrid 1994, pp. 73-84.EADEM, "Absque Deo nihil possumus". Los Khevenhüller y España. Los embajadores Hans y Franz Christoph Khevenhüller y las Ordenes Militares españolas, "La Casa del Rey. Cuatro siglos de Historia", Madrid 1997, pp. 45-80.- EADEM, Santiago, Calatrava, Alcántara e Montesa: dalla Riconquista alla Riforma, "Storia religiosa della Spagna, Centro Ambrosiano-ITL, ed. por Agostino Borromeo, Milano 1998, pp. 107-132.
} 

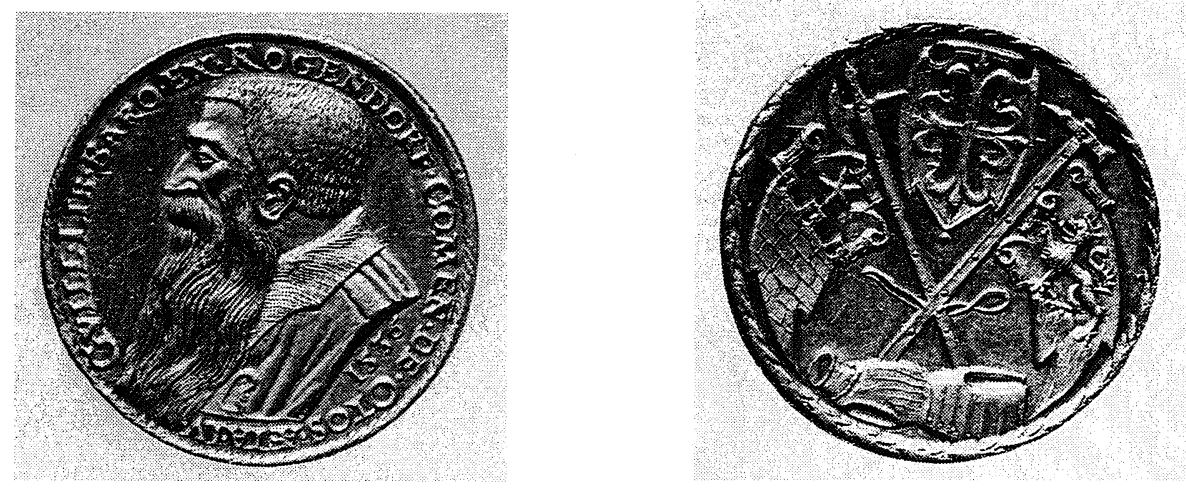

Fig. 1. Moneda con la efigie de Wilhelm von Rogendorf (Museo de Bellas Artes, Viena, Münzkabinett, Inv. 14579 bB).

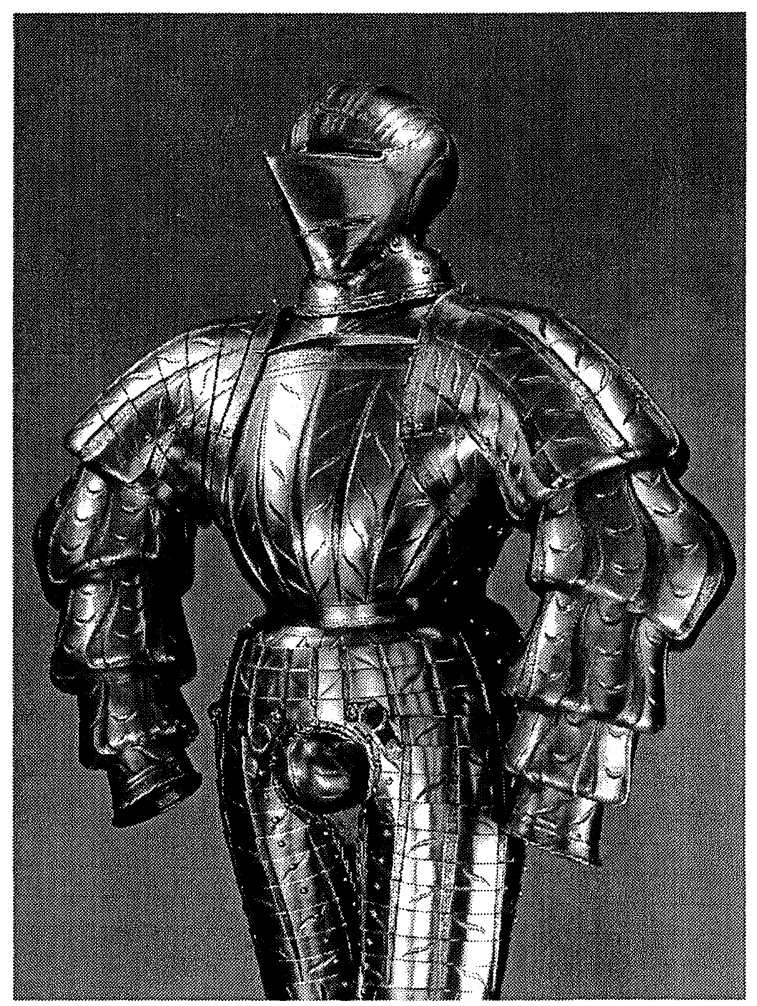

Fig. 2. Armadura de Wilhelm von Rogendorf, alrededor de 1525 (Museo de Bellas Artes, Viena, Hofjagd- und Rüstkammer, Inv. A 374). 


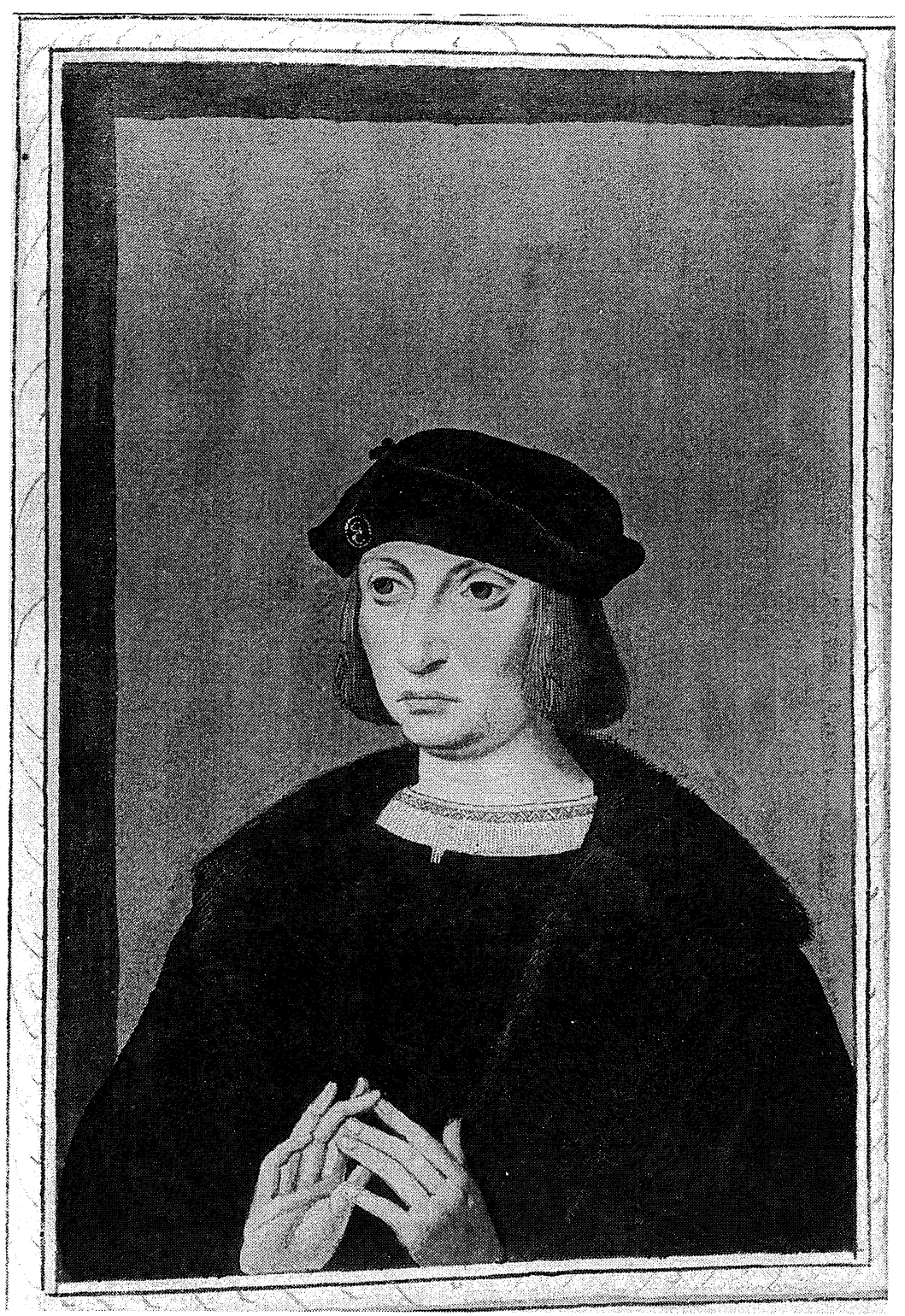

Fig. 3. Retrato de Wilhelm von Rogendorf. Portraitbuch (Libro de retratos) de Hieronymus Beck von Leopoldsdorf (Museo de Bellas Artes, Viena, Gemäldegalerie, Inv. GG 9691 fol. 357). 


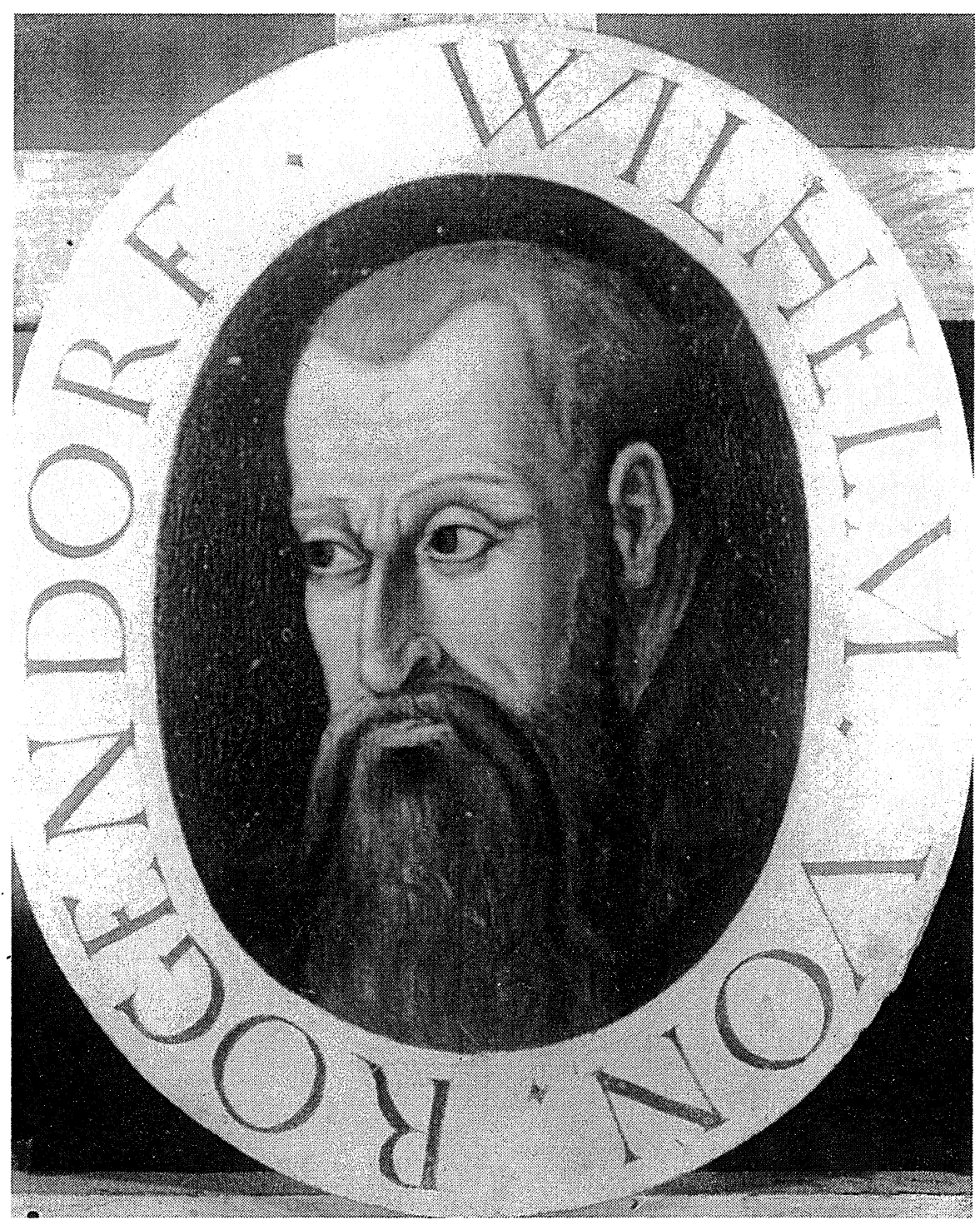

Fig. 4. Retrato oval de Wilheim von Rogendorf (Museo de Bellas Artes, Viena, Gemäldegalerie, Inv. GG 6863) 


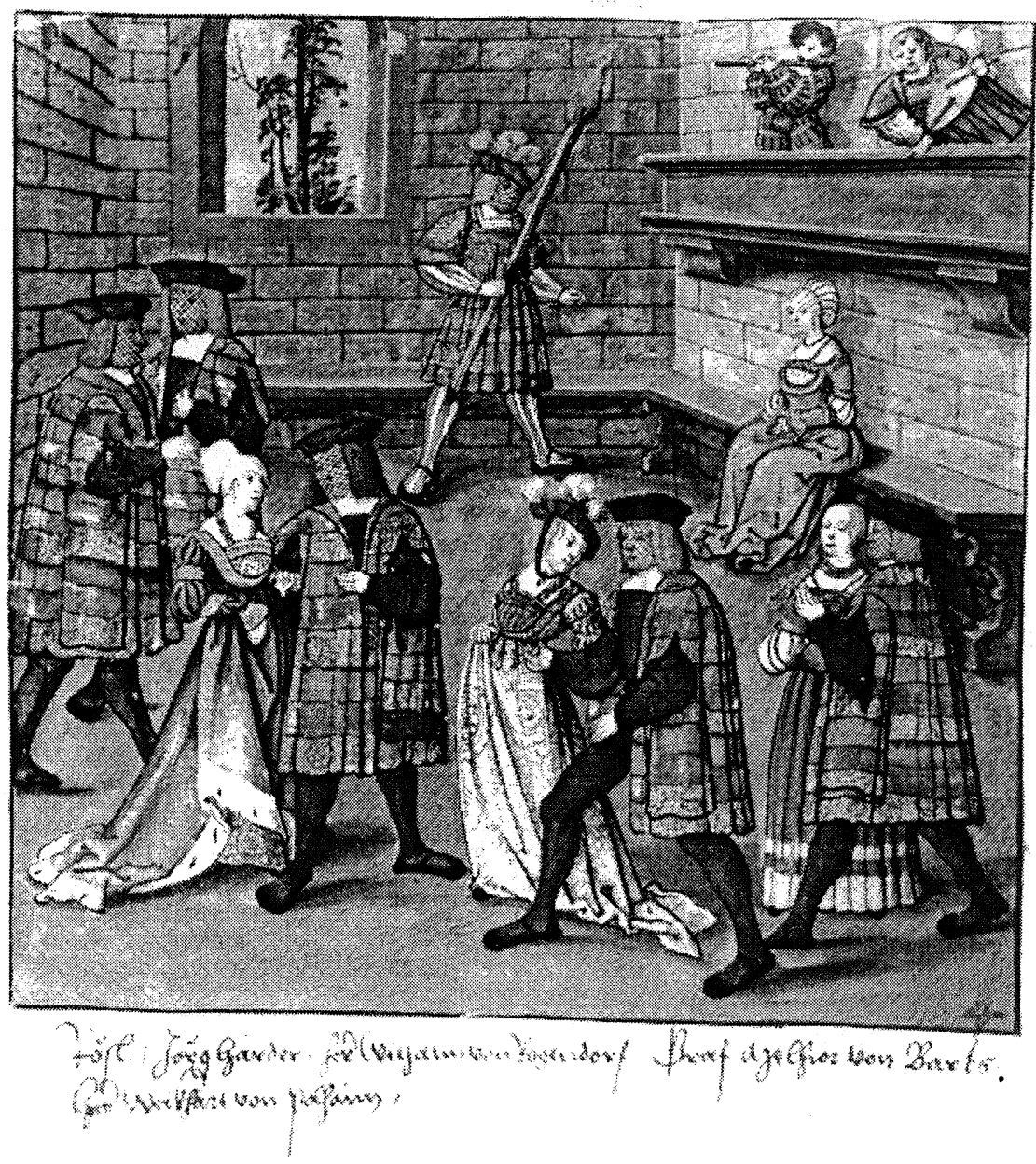

Fig. 5. Dibujo en el libro "Freydal" del emperador Maximiliano I, con Wilhelm von Rogendorf en una fiesta de máscaras (Museo de Bellas Artes, Viena, Hofjagd- und Rüstkammer, Inv. NR. K 5073 fol. 4). 


\section{RÉSUMÉ}

L'article essaie de tracer un bref profil biographique de Wilhelm von Rogendorf, noble dont la famille, originaire de Styrie, s'est établie en Basse-Autriche au milieu du XVI ${ }^{\text {ieme }}$ siècle. Depuis son enfance au service des Habsbourg, il fut page de Philippe Le Beau dans les Pays-Bas, et exerça des charges importantes auprès des empereurs Maximilien ${ }^{\mathrm{I}}$, Charles Quint, avec qui il était très lié, et Ferdinand $\mathrm{I}^{\text {er. }}$. Les missions militaires et diplomatiques l'amenèrent à voyager dans toute l'Europe, defendant les intérêts des Habsbourg contre les Vénitiens, les Français, les Mauresques de Valence et les Turcs. Des sources inédites nous permettent d'assurer qu'il est resté en Espagne de 1522 à 1528, et qu'il acquit une grande connaissance du pays, quand il voyagea partout où se trouvait l'Empereur. Son séjour dans la forteresse de Calatrava la Nueva, pour accéder à l'Ordre concédé par Charles Quint ainsi qu'au titre de Commandeur de Otos, l'ont fait participer aux institutions les plus représentatives de la Couronne de Castille. De retour en Europe centrale, Wilhelm von Rogendorf fut le précurseur d'une noblesse autochtone qui trouva dans les Ordres Militaires espagnols, l'expression externe d'une identité idéologique dans la lutte séculaire contre les Musulmans, soit dans la Péninsule, soit contre les Turcs à l'autre extrême des pays habsbourgeois, et dans le passage du Moyen Âge à une période Moderne dans la lutte contre les protetants.

\section{SUMMARY}

The article sets out to give a brief biographical sketch of nobleman Wilhelm von Rogendorf, whose family came from Styria and settled in Lower Austria in the middle of the XVth Century. Serving the Hapsburgs from chilhood, he was page to Phillip the Fair in the Low Countries and filled various offices under Emperors Maximilian I, and Charles V, to whom he was linked by a special relationship, and Ferdinand I. Military and diplomatic missions took the Austrian nobleman all over Europe, defending the interests of the Hapsburgs against the Venetians, the French, the Valencian Moriscos and the Turks. Unpublished sources show that he stayed in Spain between 1522 and 1528, which enabled him to get to know the country very well. For this, he travelled to where the Emperor was. His stay at the fortress of Calatrava la Nueva to obtain the habit of the Order, granted by Charles $V$ together with the Commandery of Otos, made him part of the institutions most representative of the mentality of the Crown of Castile. On his return to Central Europe, Wilhelm von Rogendorf formed - under Ferdinand I- the core of a native nobility which found, in the habits of the Spanish Military Orders, the outward expression of an ideological identity in the secular struggle against the Moslems taking place at that time on the Península and against the Turks on the other extreme the Hapsburg empire, as well as in the struggle against the Protestants during the transition from the Mediaeval to the Modern world. 